\title{
GCU
}

Glasgow Caledonian

University

University for the Common Good

\section{An exploration of patient satisfaction with and experience of a sexual abuse survivors clinic}

Birdi, Gurkiran ; Caswell, Rachel J.; Ross, Jonathan D.C.; Pattison, Helen; Ayinde, Oluseyi; Lorimer, Karen

Published in:

International Journal of STD and AIDS

DOI:

$10.1177 / 09564624211055962$

Publication date:

2022

Document Version

Author accepted manuscript

Link to publication in ResearchOnline

Citation for published version (Harvard):

Birdi, G, Caswell, RJ, Ross, JDC, Pattison, H, Ayinde, O \& Lorimer, K 2022, 'An exploration of patient satisfaction with and experience of a sexual abuse survivors clinic', International Journal of STD and AIDS, vol. 33, no. 2, pp. 180-185. https://doi.org/10.1177/09564624211055962

\section{General rights}

Copyright and moral rights for the publications made accessible in the public portal are retained by the authors and/or other copyright owners and it is a condition of accessing publications that users recognise and abide by the legal requirements associated with these rights.

Take down policy

If you believe that this document breaches copyright please view our takedown policy at https://edshare.gcu.ac.uk/id/eprint/5179 for details of how to contact us. 


\section{An Exploration of Patient satisfaction with and experience of a Sexual Abuse Survivors Clinic}

Gurkiran Birdi ${ }^{1}$, Rachel J Caswell ${ }^{2}$, Jonathan D C Ross ${ }^{2}$, Helen Pattison ${ }^{1+}$, Oluseyi Ayinde ${ }^{2}$, Karen Lorimer $^{3}$

${ }^{1}$ School of Life and Health Sciences, Aston University, Birmingham, B4 7ET

${ }^{2}$ Sexual Health and HIV Medicine Department, University Hospitals Birmingham NHS Trust, B15 2TH

${ }^{3}$ School of Health \& Life Sciences, Glasgow Caledonian University, Cowcaddens Road, Glasgow, Scotland, G4 OBA

† Deceased 14 March 2021

\section{Correspondence to}

Oluseyi Ayinde

University Hospitals Birmingham NHS Foundation Trust, Birmingham, B15 2TH, UK.

oluseyi.ayinde@uhb.nhs.com

\section{Declaration of conflict of interests}

JDCR reports personal fees from GSK Pharma and ownership of shares in GSK Pharma and AstraZeneca Pharma; and is lead author of the UK and European Guidelines on Pelvic Inflammatory Disease; is a Member of the European Sexually Transmitted Infections Guidelines Editorial Board; is a Member of the National Institute for Health Research Funding Committee (Health Technology Assessment programme). He is an NIHR Journals Editor and associate editor of Sexually Transmitted Infections journal. He is an officer of the International Union against Sexually Transmitted Infections (treasurer), and a charity trustee of the Sexually Transmitted Infections Research Foundation. RJC is a charity trustee of the Sexually Transmitted Infections Research Foundation. She is also lead clinician for Sexual violence and Domestic abuse services in Umbrella Sexual Health Services. All other authors declare no competing interests.

\section{Author Contributions}

RJC conceived the study. KL, GB, JDCR contributed to the design of the study. GB performed the interviews and analysis. GB, OA drafted the manuscript. RJC JDCR OA KR reviewed the draft. All authors approved the final manuscript. 


\section{An Exploration of Patient satisfaction with and experience of a Sexual Abuse Survivors Clinic}

Keywords: Sexual Health; Qualitative research; Health services research; Treatment

\section{Abstract}

Background: The scale and extent of sexual violence perpetrated in the UK is being increasingly acknowledged. Support after the initial disclosure, is often sought in NHS Sexual Health clinics. The purpose of this service evaluation was to explore patient satisfaction and experience amongst sexual health clinic attendees who disclosed sexual violence and were subsequently managed in a specialist sexual abuse survivors clinic.

Methods: Semi-structured interviews were conducted with ten service users and interview transcripts were analysed using interpretative phenomenological analysis (IPA) to assess users' experiences within the clinic.

Results: Participants were all female (aged 18-54 years) and had experienced sexual violence between 2 weeks and 15 years prior to interview, and the majority self-identified as White British (6/10). IPA analysis revealed three distinct overarching themes which were important to this group of patients when evaluating their care: delivery of care in the context of judgement and stigma, aspects of care identified as healing or harmful to recovery, and the importance of the processes of providing care.

Conclusions: Understanding the experiences of sexual violence survivors in healthcare settings can optimise the provision of patient-oriented care and support. This includes ensuring the service user is in control of the consultation, the risks of re-traumatisation are minimised, and individuals receive relevant and accurate information but in a manageable volume and format.

\section{Suggestions for service delivery}

- Address service level barriers that survivors face when accessing care after sexual violence, for example ensure patients do not have to repeat their reason for attendance to multiple healthcare staff.

- Healthcare staff require dedicated training to respond to the needs of survivors of sexual violence.

- An integrated approach incorporating both medical and specialised third sector support can provide a range of relevant services, but should be optimised to ensure clarity for those accessing services.

\section{Introduction}

The scale of sexual violence perpetrated in the United Kingdom is being increasingly recognised. ${ }^{1}$ First disclosures are commonly made in NHS sexual health clinics where up to $17 \%$ of female attendees report having experienced sexual violence. ${ }^{2}$ Although many survivors find their encounters with health 
care professionals to be beneficial, for some the experience is suboptimal due to lack of staff, inadequate experience or training, delays in accessing care, or a poor physical environment. ${ }^{34}$ Enabling service user empowerment and greater control during the consultation process can also improve wellbeing. ${ }^{5}$ Qualitative studies have highlighted the convenience of attending a sexual health clinic to be important in addition to positive staff attitudes in this setting, ${ }^{6}$ however, data exploring the specific experiences of sexual violence survivors attending sexual health services are limited.

'Umbrella' delivers sexual health services to a population of 1.1 million in Birmingham and Solihull in the United Kingdom. Attendees are asked routinely about a history of sexual violence which has led to an increased number seeking support, equating to more than one child per week and more than one adult per day (local audit data). In response, a specialised Abuse Survivors Clinic (ASC) was established which is provided in partnership with a third sector organisation, the Rape and Sexual Violence Project (RSVP). The ASC team comprises an experienced doctor, Health Advisor and RSVP Independent Sexual Violence Advocate (ISVA). The ISVAs' role includes making clients aware of their legal rights, explaining reporting options, accompanying the individual to medical appointments, explaining the criminal justice process/system and attending court with them, and assistance in completing criminal injuries compensation forms.

The aim of this service evaluation was to assess service users' experiences following attendance at the Abuse Survivors Clinic to inform and improve the future delivery of the service.

\section{Methods}

\section{Participants and recruitment}

A convenience sample of sexual violence survivors were identified between September 2017 and April 2018 from sexual health clinic attendees. The service evaluation was advertised on posters in the Umbrella sexual health clinic and participants who responded to the advertisements or expressed interest to their health care professional were invited to participate. Participant information sheets were provided prior to the day of interviewing by healthcare staff at Umbrella. All participants provided informed written consent. Participant confidentiality and anonymity were maintained throughout the study. Participants received a $£ 25$ shopping voucher in compensation for their time. The protocol was reviewed by University Hospitals Birmingham NHS Foundation Trust and assigned to be a service evaluation (approval ID- CARMS-13384).

\section{Interviews and analysis}

In-depth, semi-structured interviews were conducted with service users by a female researcher (GB) who was experienced in qualitative interview techniques. A single interview was conducted - one to 
one with each participant in a private room at the clinic, and audio was recorded. An interview guide was developed from qualitative research conducted on similar participant groups and findings from related quantitative studies ${ }^{7-9}$. Open-ended questions facilitated discussion on the lived experience of being seen in the ASC including feelings about attendance, patient satisfaction, referral pathways and suggested improvements to the service. The interview style was non-directive and consisted of a dynamic reflection, with talk flowing from general accounts of the individual's experience to detailed accounts of specific thoughts and feelings. Therefore, although the content of each interview varied, the interview style remained consistent. Interviews lasted between 45 and 90 minutes. Audio transcripts were not returned to participants for review.

Interpretive phenomenological analysis (IPA) was employed to explore participants' accounts of their experiences and the meanings they may attach to them. IPA is a method used to explore the informants' views of the world and to adopt as far as possible an "insider perspective" ${ }^{10}$ recognising that the research exercise is a dynamic process. ${ }^{11}$ The data were analysed and coded initially by one data coder. NVivo 11 Software was used to manage and store the data and themes were derived directly from the data.

\section{Results}

Ten female participants who agreed to participate in the study were recruited (Table 1). Three overarching themes were identified and summarised the experiences and satisfaction of the ASC service users, including: delivery of care in the context of judgement and stigma; aspects of care identified as healing or harmful to recovery; and importance of the processes of providing care.

Table 1. Participant characteristics

\begin{tabular}{|c|c|c|c|c|}
\hline Participant & Ethnicity & Age & $\begin{array}{c}\text { Time since abuse } \\
\text { occurred }\end{array}$ & $\begin{array}{l}\text { Pathway to Abuse } \\
\text { Survivors Clinic }\end{array}$ \\
\hline ASC01 & White British & $18-24$ & 6 weeks & $\begin{array}{l}\text { Through another sexual } \\
\text { health clinic appointment }\end{array}$ \\
\hline $\mathrm{ASCO2}$ & White British & $18-24$ & 15 years & Online via website \\
\hline ASC03 & Indian British & $25-44$ & 2 weeks & $\begin{array}{l}\text { Through another sexual } \\
\text { health clinic appointment }\end{array}$ \\
\hline
\end{tabular}




\begin{tabular}{ccccc}
\hline Participant & Ethnicity & Age & $\begin{array}{c}\text { Time since abuse } \\
\text { occurred }\end{array}$ & $\begin{array}{c}\text { Pathway to Abuse } \\
\text { Survivors Clinic }\end{array}$ \\
ASC04 & Pakistani British & $45-54$ & $<3$ months & $\begin{array}{c}\text { Through another sexual } \\
\text { health clinic appointment }\end{array}$ \\
\hline ASC05 & Black British & $45-54$ & 10 years & RSVP \& ISVA \\
\hline ASC06 & Black British & $25-34$ & 10 years & RSVP \\
\hline ASC07 & White British & $18-24$ & 7 years & $\begin{array}{c}\text { Through another sexual } \\
\text { health clinic appointment }\end{array}$ \\
\hline ASC08 & White British & $25-44$ & 10 years & RSVP \\
\hline ASC09 & White British & $45-54$ & 15 years & Through another sexual \\
& & & & health clinic appointment \\
\hline ASC10 & White British & $18-24$ & $<3$ months & RSVP \\
\hline
\end{tabular}

RSVP = Rape and Sexual Violence Project; ISVA = Independent Sexual Violence Advocate

\section{Delivery of care in the context of judgement and stigma}

This encompassed anticipated and actual reactions that participants had experienced from friends and family, medical staff, the police, and society. The attitudes expressed were predominantly negative.

'Others just don't get what it [abuse] does' [ASCO8].

Some participants also felt specific stigma was associated with attending a 'sexual health' clinic,

'it's clearly a clinic for people with like sexually transmitted diseases and stuff, so I don't really feel comfortable bringing anyone with me or anyone seeing me go in'. [ASC10]

However, many women felt a sense of relief at being able to verbalise their experiences even though they had feelings of discomfort in doing so. Some described feeling afraid of the perpetrator, with one woman explaining that the perpetrator was 'well-known' in the community which would never let her 'live it down'. There was also a fear that describing events to the clinic staff would recall feelings of shame and judgement.

One woman was abused by a family member and had been very concerned about anyone finding out about her abuse. She had not verbalised her experiences prior to the ASC, but after visiting the clinic 
she slowly started to 'open up' about it. The fear of others becoming aware of the abuse raised concerns around confidentiality. One survivor stated that reinforcing anonymity and confidentiality at the ASC would have been beneficial.

When I wasn't told anything that it would stay anonymous. ....If I had been reassured on that I could just be like a code instead of my name then that would've encouraged me ... But I need to see it in writing that my name will never, ever be revealed. [ASCO3]

In contrast, another participant felt she had been encouraged by the ISVA to remain anonymous when considering formal reporting of the sexual violence:

Why would I want to do it anonymous? I said, "you're going to put his face on there with none of my details" [ASCO4].

\section{Aspects of care identified as healing or harmful to recovery}

Many felt that a trusting therapeutic relationship was central to recovery and were appreciative that the doctor displayed interest and concern. This enabled them to feel more confident within the consultation and become an active participant in the interaction. Central to this experience was being 'treated like a human being'.

You feel heard not just listened to [ASCO9]

They were very sensitive and what I liked about it was that the human side of it was nice [ASC05]

And feeling listened to, understood, supported and cared for.

They're very understanding like caring. It, sort of, reminded me of, like, a motherly figure or like a big sister figure [ASCO1].

Another factor in this therapeutic relationship was a sense of control. Being treated with 'the human touch' meant being involved in treatment decisions. One woman said that being an abuse victim results in having choice taken away, but another felt reassured by being able to leave the service at any point or come back to the clinic for follow-up appointments if required, which was in contrast to previous care when she had little or no say.

I liked that the point that at any point along the examination or even if I was in the waiting room and it was too much, I could say and I didn't feel as if I would be wasting anyone's time" [ASCO5] 
One woman had felt coerced into taking emergency contraception after the rape, highlighting the importance of service provision that ensures patients feel empowered in a consultation. She was initially assessed in a general sexual health clinic immediately prior to being seen in the ASC.

My first concern was to get HIV or AIDS from it. That was my main concern. Pregnancy, I can deal with. But HIV, I can't. So that was more important for me that day [ASCO3]

Comparisons were made on how experiences at the ASC differed from other health care encounters. All those who mentioned past experiences with doctors agreed that the ASC, being a 'specialised service', was better equipped to meet their needs. Visiting a regular GP meant having to 'squeeze in to 10 minutes'. For several of these women, ASC was described as the first formal support provider that they felt had treated them like "real" people. At ASC, they felt respected, safe, and able to begin the healing process.

The thing that I liked the most is that it was unrushed and I felt like a person [OK] not a case study for a doctor. And that helped me a great deal because, like I said before, in the past I have been examined and I have felt nothing more than a slab of meat [ASCO5]

Another also compared the care given at ASC with previous health care encounters and discussed how other health professionals made her feel 'ashamed' and 'uncomfortable', as opposed to the doctor at the ASC who made her feel like they 'were family'.

\section{Importance of the processes of providing care}

Booking of and the process leading up to and after an appointment

There was a sense of uncertainty and apprehensiveness associated with attendance and this may have made the booking process more challenging. For example, one woman conveyed being apprehensive about the process of accessing the ASC, describing 'putting the phone down' multiple times before successfully booking an appointment. This anxiety and fear associated with making an appointment was also described by others, although preconceptions were not borne out when contact was made.

'She was actually offering ideas and things that I felt like were good at that moment. And she was like...yes, I felt like she was actually there listening' [ASCO2]

Having an RSVP advisor contact the clinic on behalf of the survivor was one way of facilitating this initial step.

Apprehension prior to the clinic attendance was commonplace. 
The only thing I had to arrange was in my mind to prepare myself, let's *face it, it was going to be an internal examination it was going to be taking blood and it was going to be, you know, for me to bare flesh in public with people I don't know. So, for all of that I had the time to prepare [ASCO5]

The name of the clinic holds significance too, one participant felt that the clinic was focused on survivors such as her, and thus felt more confident attending:

I don't want to use the word victim because I'm not victim, I'm a survivor. But it was survivorcentred and that was nice [ASCO5]

Although many participants left the ASC appointment feeling composed, a few felt additional followup would have been beneficial, or being given more opportunity to compose themselves after the consultation but before leaving the ASC.

I wouldn't have want to just go and say "Goodbye *RSVP advisor*" and then go home on the bus. I wouldn't have felt safe. I was all a wreck, you know, I couldn't think straight. [ASCO9]

Types of support offered

Some women attended with the erroneous expectation that the ASC would be a counselling session. One woman felt that more information should have been provided to clarify the role of the clinic.

I was under the impression... I think you need to be told what's happening prior to it happening if that makes sense. I was thinking I was going to counselling. I definitely wasn't, at all [ASCO6] Another felt confused and overwhelmed by the transfer within the ASC from the doctor to the ISVA. It made her wonder if there was 'something more serious' wrong with her although she later understood that the ISVA was part of the ASC service.

The provision of appropriate information was key for many. A source of pride for participants was being able to make sense of new, and often complicated, information by drawing on prior knowledge and beliefs. However, one participant was hesitant to use any of the information provided because of concerns about having to verbalise her abuse to more people.

They gave me leaflets. Obviously, there was numbers on some, like I can even call this at any point but it's a big deal to just do that and then you are going to have to do it from the beginning and, if you are to call, then it's probably going to be someone totally different every time [ASCO6] 
The time interval following sexual violence was an important factor in information assimilation and those with recent experiences were more able to take on-board new information. According to some, the ISVA was also more useful if the abuse was recent.

The gist I seemed to get was that they tend to work more with people who, like, the abuse has been really recent. So, I think... the police case and stuff for me wasn't something I wanted to re-open after a long time [ASCO7]

\section{Physical environment}

Few women raised issues about the physical surroundings at the ASC. We did not directly ask about the physical environment, and only a few spontaneously offered their views towards it, including one who felt the room in which she saw the doctor was 'too clinical', and another who described the size of the room:

She was like in a cupboard. I thought I was going into a separate room but it was literally like a little cupboard [ASCO6]

\section{Discussion}

This qualitative study has provided rich insight into the experiences of attendees at a specialist sexual abuse survivors' clinic. Health professionals have the unique opportunity to prevent and/or alleviate "secondary victimization" - a phenomenon which describes when rape survivors are exposed to victim-blaming behaviours or attitudes, where the experience may feel like a "second assault" or a "second rape" ${ }^{12-15}$ Although we did not assess post-assault psychological outcomes (e.g., depression, post-traumatic stress disorder), we found that through the ASC many of the sexual assault survivors felt reassured and developed a level of trust with healthcare professionals suggesting that positive experiences with the ASC promote recovery and emotional well-being.

Overall, three themed insights were identified. First, the challenge of providing care in the context of judgement and stigma associated with sexual violence, which can create barriers for those who want to access help. Judgement comes not only from society, communities and families but also from survivors themselves. Within specialist sexual health services such as the ASC there needs to be an appreciation of these barriers when promoting and delivering the service, and during staff training. Evidence from studies of healthcare after domestic abuse affirm the importance of staff contributing to developing trusting and respectful relationships. ${ }^{16}$ Operating an ASC within a sexual health service setting may in itself create a barrier to access but also provides advantages in permitting self-referral, access to specialist staff, and testing for sexually transmitted infections which attendees value. 
Survivors tend to seek healthcare more frequently than women who have not experienced abuse, including the use of sexual health services, ${ }^{17}$ such that the fostering of trust and assurance of confidentiality when delivering sexual health care could encourage survivors to disclose sexual violence.

Next, the evaluation identified specific aspects of care that facilitated 'healing to recovery' following sexual violence, including the perception of genuine empathy during consultation, a sense of being in control and the provision of service that is fit for purpose. Some participants contrasted health care professionals at the ASC to previous health encounters, and described the ASC staff as better 'equipped' and more 'understanding and sensitive', as well as 'non-judgemental' in comparison. Whilst establishing an emotional connection has been noted as important when responding to survivors of intimate partner abuse ${ }^{16}$ here we also see it in relation to healthcare after sexual violence. Although often unintentional, in some instances victim blaming behaviours are overt as professionals may explicitly hold survivors responsible for the assault, doubt the veracity of survivors' stories, or minimize the seriousness of the crime. ${ }^{13}$ Participants felt they were given control at the ASC, which bolstered their confidence in taking further steps to recovery. The importance of (re)gaining control in healthcare experiences after sexual violence is consistent with other work. ${ }^{18}$ Also, some felt better equipped to consider reporting the assault to the police when support from an ISVA was available.

Finally, we found that the mechanics of care provision mattered to attendees including the logistics around booking an appointment, clarity on the types of support on offer, and the physical environment where consultations took place. Many participants expressed anxiety prior to booking an appointment or their first attendance, and it is possible that the option for automated bookings following referral to the ASC may ameliorate such anxieties. For some individuals part of the reason for their attendance at the ASC was their continued search for relevant support and it is important that those offering specialist services should be transparent about what services are being offered at the time of booking. The provision of appropriate mental health care following sexual violence is also of importance to this group, particularly when access to community-based mental health care is often limited. ${ }^{319}$ A few service users also expressed a preference for a more open or relaxed (informal) physical environment.

\section{Conclusions}

Survivors of sexual violence perceived the emotional care provided to be particularly important, and additional training for clinic staff may be required for optimal service delivery. Care for survivors is made more challenging because of the societal judgment and stigma that is still associated with being 
a victim of sexual violence, training needs to equip staff with an understanding of the systematic nature of the trauma and how to avoid secondary victimization. An integrated approach of both medical and specialised third sector support can provide a range of relevant services but should be managed effectively to prevent overwhelming service users.

\section{Acknowledgements}

We would like to thank all participants who volunteered for the study

\section{Funding}

This study was supported by a Research and Development Grant through Umbrella Sexual Health Service. 


\section{References}

1. Phipps A, Smith G. Violence against women students in the UK: time to take action. Gender and Education 2012;24(4):357-73. doi: 10.1080/09540253.2011.628928

2. White J, Biros N, Holland D. P94 Prevalence and correlates of sexual violence in female attendees at genitourinary medicine clinics. Sexually Transmitted Infections 2012;88(Suppl 1):A41-A41. doi: 10.1136/sextrans-2012-050601c.94

3. Campbell R, Ahrens CE, Sefl T, et al. Social reactions to rape victims: healing and hurtful effects on psychological and physical health outcomes. Violence Vict 2001;16(3):287-302. [published Online First: 2001/07/05]

4. Sigurdardottir S, Halldorsdottir S, Bender SS, et al. Personal resurrection: female childhood sexual abuse survivors' experience of the Wellness-Program. Scand J Caring Sci 2016;30(1):175-86. doi: 10.1111/scs.12238 [published Online First: 2015/06/04]

5. Barros Lde A, Albuquerque MC, Gomes NP, et al. [The (un)receptive experiences of female rape victims who seek healthcare services]. Rev Esc Enferm USP 2015;49(2):193-200. doi: 10.1590/s0080-623420150000200002 [published Online First: 2015/05/21]

6 . Weston R, Dabis R, Ross JD. Measuring patient satisfaction in sexually transmitted infection clinics: a systematic review. Sex Transm Infect 2009;85(6):459-67. doi: 10.1136/sti.2009.037358 [published Online First: 2009/10/15]

7. Hoopes AJ, Benson SK, Howard HB, et al. Adolescent Perspectives on Patient-Provider Sexual Health Communication: A Qualitative Study. J Prim Care Community Health 2017;8(4):332-37. doi: 10.1177/2150131917730210 [published Online First: 2017/09/21]

8. Lindberg C, Lewis-Spruill C, Crownover R. Barriers to sexual and reproductive health care: urban male adolescents speak out. Issues Compr Pediatr Nurs 2006;29(2):73-88. doi: 10.1080/01460860600677577 [published Online First: 2006/06/15]

9. Miles K, Penny N, Power R, et al. Comparing doctor- and nurse-led care in a sexual health clinic: patient satisfaction questionnaire. Journal of Advanced Nursing 2003;42(1):64-72. doi: https://doi.org/10.1046/i.1365-2648.2003.02580.x

10. Smith JA. Beyond the divide between cognition and discourse: Using interpretative phenomenological analysis in health psychology. Psychology \& Health 1996;11(2):261-71. doi: 10.1080/08870449608400256

11. Jonathan AS, Jarman M, Osborn M. Doing Interpretative Phenomenological Analysis. Qualitative Health Psychology: Theories and Methods. London: Sage 1999.

12. Campbell J. Empowering survivors of abuse : health care, battered women and their children. Thousand Oaks, Calif. London: Thousand Oaks, Calif. London : SAGE 1998.

13. Madigan L. The second rape : society's continued betrayal of the victim. New York : Toronto : New York: New York : Lexington Books Toronto : Maxwell Macmillan Canada New York : Maxwell Macmillan International 1991.

14. Martin PY, Powell RM. Accounting for the "Second Assault": Legal Organizations' Framing of Rape Victims. Law \& Social Inquiry 1994;19(4):853-90.

15. World Health Organization. Responding to intimate partner violence and sexual violence against women: WHO clinical and policy guidelines: World Health Organization, 2013.

16. Tarzia L, Bohren MA, Cameron J, et al. Women's experiences and expectations after disclosure of intimate partner abuse to a healthcare provider: A qualitative meta-synthesis. BMJ Open 2020;10(11):e041339. doi: 10.1136/bmjopen-2020-041339

17. Kazmerski T, McCauley HL, Jones $\mathrm{K}$, et al. Use of reproductive and sexual health services among female family planning clinic clients exposed to partner violence and reproductive coercion. Matern Child Health J 2015;19(7):1490-6. doi: 10.1007/s10995-014-1653-2 [published Online First: 2014/11/25] 
18. Caswell RJ, Ross JD, Lorimer K. Measuring experience and outcomes in patients reporting sexual violence who attend a healthcare setting: a systematic review. Sex Transm Infect 2019;95(6):419-27. doi: 10.1136/sextrans-2018-053920 [published Online First: 2019/06/21]

19. Goldberg D. Training general practitioners in mental health skills. International Review of Psychiatry 1998;10(2):102-05. doi: 10.1080/09540269874853 